\title{
EL LLAMADO «NUEVO ORDEN INTERNACIONAL» VISTO DESDE ESPAÑ**
}

\author{
CARLOS JIMÉNEZ PIERNAS \\ Catedrático de Derecho Internacional Público \\ y Relaciones Internacionales.
}

\section{Introducción}

Los avatares del escalafón han determinado que la lección inaugural del presente curso 1992-93, en nuestra Facultad de Derecho, corresponda impartirla a un Catedrático de Derecho Internacional Público y Relaciones Internacionales. Aunque 1992 ha sido para España un año señalado por varias razones, no cabe duda que para un profesor de Derecho Internacional Público y Relaciones Internacionales la razón principal no puede ser otra que la conmemoración del descubrimiento de América y de la gran aventura histórica que para España representó la conquista y administración durante tres siglos de un vasto continente.

Es sabido que la forma histórica y más importante del ordenamiento internacional, vulgarmente denominada D. I. clásico tal y como ha perdurado hasta 1945, tuvo sus raíces en la Europa Occidental del siglo XVI. Y que de este siglo arranca también, no por casualidad, la reflexión doctrinal más significativa sobre el entonces llamado Derecho de Gentes, en cuya fase constitutiva original, que culminó en 1615 con la obra del holandés Hugo Grocio, desempeñó un papel precursor fundamental la Escuela Española del Derecho de Gentes ${ }^{1}$. Esta Escuela Española, que tuvo parte decisiva en la invención del D. I., una de nuestras más reconocidas aportaciones a la cultura universal junto con nuestra importante contribución en la génesis del Estado moderno y la colonización de gran parte de América, sin duda debió mucho en su origen y desarrollo al reto intelectual que entonces supuso hacer frente a problemas enjundiosos como la legitimidad de la conquista, el trato debido a los indios y la defensa de sus más elementales derechos, entre otros problemas.

Viene a cuento recordar que la articulación del pensamiento de los teólogosjuristas españoles adoptó, en significativas ocasiones, la forma de relecciones. Ya «en el siglo XV se entendía por relectio o repetitio la disertación magistral que los

*Texto de la lección inaugural dictada en el acto de apertura oficial del curso académico 1992-1993 en la Facultad de Derecho de la Universidad de Alicante, el día 21 de octubre de 1992.

${ }^{1}$ Stadmuller, G., Historia del Derecho Internacional Público, trad. de F. F. Jordán Santa Eulalia y rev. de A. Truyol Serra, Madrid 1961, Cap. 17, sobre todo pp. 146-147. 
catedráticos en propiedad estaban obligados a pronunciar una vez al año en un acto académico solemne ante la propia facultad e, incluso, ante toda la Universidad sobre alguno de los temás más importantes de las lecciones desarrolladas durante el curso $»^{2}$. Fue así como Francisco de Vitoria, uno de los más destacados maestros de la facultad de Teología de la Universidad de Salamanca, que se había convertido en la Universidad más célebre del imperio, ofreció a la comunidad universitaria sus célebres relecciones De Indiis y De iure belli, precursoras del moderno Derecho Internacional.

La obligación del cumplimiento de la relectio o repetitio venía impuesta por las Constituciones otorgadas por el papa Martín V a la Universidad de Salamanca en 1422. La mayoría de profesores dejaba que desear en el cumplimiento de dicha obligación y se limitaban a cubrir el expediente, careciendo sus relecciones de mérito y actualidad. Otros docentes preferían antes ver reducidos sus emolumentos con la multa preceptuada en las susodichas Constituciones por el incumplimiento de esa obligación (diez francos del salario que correspondiera), antes que esforzarse en preparar la relección. «A Vitoria se debe haber sacado de la atonía en que se encontraba esta institución y haberla elevado a uno de los actos académicos de mayor relieve en la vida universitaria, gracias al interés que puso, primero, en escoger temas importantes y de actualidad que despertasen el interés del público universitario, y en segundo lugar, por el elevado nivel científico con que las desarrolló». A ejemplo suyo, sus discípulos intentaron mantener el prestigio de la institución, asumiendo con esmero la obligación de la relectio o repetitio tanto en España como en el Nuevo Mundo. Es el caso del agustino Alonso de Veracruz en la recién creada Universidad de México, que trató de abordar en la cátedra temas prácticos y de actualidad, sin huir —-por supuesto- de los más controvertidos. Así, en el primer curso académico de 1553-1554, eligió la licitud de las encomiendas y los derechos respectivos de españoles y nativos sobre la propiedad y el gobierno de los territorios americanos. Alonso de Veracruz amplió notoriamenmte poco después el texto original de esta repetición, hasta formar un tratado (De dominio infidelium et iusto bello), tal como ha llegado hasta nosotros tras permanecer inédito durante cuatro siglos ${ }^{3}$.

En ese tratado, Alonso de Veracruz planteó la legitimidad de la conquista y abordó la regulación de la conducta práctica entre españoles y nativos, no sobre la base de unos derechos conferidos por la conquista sino conforme a los principios de la justicia, del derecho natural y las exigencias de la moral cristiana tradicionalmente defendidos por nuestros teólogos-juristas del siglo XVI, genuinos representantes todos ellos de la independencia intelectual universitaria frente a los poderes públicos

${ }^{2}$ Cerezo de Diego, P., «Influencia de Alonso de Veracruz, OSA en la Universidad de México», en Actas del Congreso Internacional V Centenario: Agustinos en América y Filipinas, Valladolid, 16-21 abril 1990, 385-411, p. 399.

3Ibíd., p. 400 para todo el párrafo, cita incluida. 
(inclusive la jerarquía eclesiástica y la Santa Inquisición) y las presiones de los encomenderos, y que introdujeron en el continente americano la libertad de expresión académica iniciada en la Universidad de Salamanca ${ }^{4}$.

Pues bien, emulando el ejemplo de nuestros muy ilustres predecesores, si no ya en el mérito y la calidad sí al menos en lo demás, pretendemos ocuparnos en esta lección inaugural de un tema sin duda importante y actual, el llamado «nuevo orden internacional» o - más abreviadamente- «nuevo orden mundial», tema que trataremos desde la atalaya o perspectiva que hoy nos ofrece nuestro propio país, desde la posición que España ocupa en el concierto de las naciones. Es un tema, además, que nos aleja de la tentación del microanálisis, de la lección pensada y hecha para ser dictada ante colegas e iniciados; es un tema que también facilita que nuestro discurso llegue a toda la comunidad universitaria, muy en particular a los estudiantes. Parece sensato que los estudiantes, y no sólo ellos, enfrentados a la gran complejidad y extraordinario dinamismo del mundo contemporáneo, prefieran exposiciones formativas que usen conceptos y categorías generales y previos antes que análisis concretos y más especializados, porque estos últimos difícilmente les permitirán entender la gran avalancha de acontecimientos muy variopintos que desfilan cotidianamente ante sus ojos cuando leen la prensa o ven un telediario.

\section{Los acontecimientos singulares de los últimos años}

Entre esa avalancha de acontecimientos hay muchos que no llaman la atención porque son desgraciadamente habituales. Son habituales, y mucho más numerosas que los conflictos bélicos internacionales habidos desde el fin de la Segunda Guerra Mundial, las guerras civiles que asolan sistemáticamente gran número de Estados. Recordemos como guerras civiles vivas las que tienen lugar en la antigua Yugoslavia, en Angola, Somalia, Afganistán o Líbano. Otras guerras civiles apenas acaban de finalizar y aún quedan sus rescoldos, como las de El Salvador y Etiopía, entre otras. Habituales son las hambrunas que asolan sistemáticamente Africa. Habituales son las graves y masivas transgresiones de los derechos humanos más fundamentales en todos los confines del planeta. Recordemos, a título ejemplar, la situación desesperada, estremecedora, que sufre la infancia en Iberoamérica a causa de la transgresión continua de sus más elementales derechos, con niños que trabajan en condiciones infrahumanas, que participan activamente en conflictos armados, que son prostituidos, vendidos, asesinados o ejecutados extrajudicialmente por miles cada año en las calles de las grandes ciudades de ese continente.

${ }^{4}$ Ibíd., pp. 407-409. También Pérez-Luño, A. E., «Los iusnaturalistas clásicos hispanos y la polémica sobre el Nuevo Mundo», en Revista de Estudios Políticos (Nueva Epoca), nº77 (Julio-Septiembre 1992), 7-31, pp. 8-10. 
Empiezan a ser habituales las noticias que nos informan sobre los riesgos de la degradación del medio ambiente, como es el caso de la deforestación paulatina, imparable, de la selva ecuatorial, bien visible en la Amazonía brasileña, el principal pulmón de nuestro planeta ${ }^{5}$. También son habituales las noticias sobre las discriminaciones y malas condiciones de vida que padecen los inmigrantes ilegales en Estados receptores de esa inmigración, inclusive España - por supuesto-. Y se hacen preocupantes por lo habituales las noticias de estos últimos meses sobre las decenas de inmigrantes magrebíes ilegales que a fe cierta han muerto ahogados en las aguas del Estrecho y del Mar de Alborán en sus desesperados intentos por entrar en España.

No obstante, entre los acontecimientos que nos han abrumado en la última media docena de años ha habido y hay algunos que sí llaman la atención por su naturaleza singular indudable.

Ese sería el caso de la desaparición de la contradicción ideológica entre Este y Oeste, que es a su vez el fin de un proceso cuyos acontecimientos más importantes han sido - por este orden - la tímida apertura política iniciada en 1985 por el entonces líder soviético M. Gorbachov, uno de cuyos hitos exteriores más espectaculares fue la firma en Washington, el 8 de diciembre de 1987, del Tratado sobre eliminación de cohetes de corto y medio alcance entre Estados Unidos y la URSS, sin duda el principio del fin de la guerra fría; la caída del Muro de Berlín la noche del 9 de noviembre de 1989 y la casi inmediata unificación alemana, acaecida el 3 de octubre de 1990; y la desaparición del Bloque Socialista, incluidos el Consejo de Asistencia Económica Mutua y el Pacto de Varsovia, este último disuelto formal y definitivamernte el 1 de julio de 1991.

Sin olvidar otros acontecimientos de desarrollo temporal casi paralelo o en todo caso inmediato a los anteriores como son la desintegración de varios Estados del antiguo Bloque Socialista, suceso que en apenas un año ha elevado considerablemente el número de Estados soberanos reconocidos en el ordenamiento internacional. En efecto, la Unión Soviética, sin duda el ejemplo principal, entró en una grave crisis tras el fallido golpe de Estado del 19 de agosto de 1991 perpetrado por el viejo aparato comunista contra el Presidente Gorbachov y la consiguiente revolución de agosto que, auspiciada por dicho fracaso, liquidó en apenas dos semanas el régimen comunista y la propia estructura estatal de la Unión Soviética, hoy descompuesta en doce Repúblicas independientes ${ }^{6}$ después de que las Repúblicas eslavas integrantes de la antigua Unión firmaran el Acuerdo de Alma Ata de 21 de diciembre de 1991, que, además de formalizar la desaparición de aquella Unión, creaba la Comunidad

\footnotetext{
${ }^{5}$ Vid. un testimonio reciente y documentado sobre este problema en Comissao Interministerial para preparaçao da Conferencia das Naçôes Unidas sobre meio ambiente e desenvolvimento(CIMA), O desafio do desenvolvimento Sustentável. Relatório do Brasil para a Conferência das Naçôes Unidas sobre Meio Ambiente e Desenvolvimento, Brasilia 1991, pp. 97-101 y 137-139.

${ }^{6}$ A saber y por orden alfabético, las Repúblicas de Armenia, Azerbaiyán, Bielorrusia, Federación de Rusia, Georgia, Kazajistán, Kirguizistán, Moldavia, Tayikistán, Turkmenistán, Ucrania y Uzbekistán.
} 
de Estados Independientes y atribuía a la Federación de Rusia el puesto permanente de la Unión Soviética en el Consejo de Seguridad.

La República Federativa de Yugoslavia entró definitivamente en crisis en 1991, culminando ésta con la secesión de hecho de las nuevas Repúblicas de Eslovenia, Croacia, Bosnia-Herzegovina y Macedonia, y el estallido de la guerra civil en Croacia primero y en Bosnia-Herzegovina después ${ }^{7}$, en ambos casos con el fin abiertamente confesado de revisar las antiguas fronteras interrepublicanas para agrupar a casi toda la población servia dentro del territorio de la nueva República de Servia y Montenegro y de paso evitar la presencia de importantes minorías en el territorio de los Estados sucesores. En cuanto a Checoslovaquia, su escisión pacífica en dos nuevos Estados (la República Checa, formada por Bohemia y Moravia, y la República Eslovaca) está prevista para el 1 de enero de 1993. Si echamos cuentas, en poco más de un año a tres antiguos Estados les han sucedido diecinueve nuevos Estados.

A esta eclosión nacionalista, impensable hace unos años, hay que sumar el primer traspiés verdaderamente serio sufrido por el proceso de integración europea, cuyo último eslabón (el Tratado de la Unión Europea o Tratado de Maastricht de 7 de febrero de 1992) ha entrado en cuarentena tras el triunfo en el mes de junio del no en el referendum danés por el que se proponía su ratificación, y el apretadísimo sí conseguido en el referendum francés en el mes de septiembre; sin olvidar las reticencias británicas, cuyo gobierno ha postergado sine die su ratificación. El proceso de integración europea ha mostrado en los últimos meses grietas, fisuras inimaginables hace sólo unos meses, cuando se nos aparecía a todos como el más inquebrantable de los destinos, aunque alejado en el tiempo.

Entendemos que estas dificultades se deben, entre otras razones, al crónico déficit democrático (mal que les pese a los euroburócratas y a los políticos en activo reluctantes al uso de esta expresión) que padecen las instituciones comunitarias. Pero el Tratado de Maastricht ${ }^{8}$ contiene sobre todo en su seno el establecimiento de la unión monetaria y de un Banco Central Europeo. Al lado de esta evidencia y en comparación con ella, la creación por ejemplo de una ciudadanía de la Unión, de la que buena parte de sus derechos ya vienen disfrutando los nacionales de los Estados miembros, es otra muestra más del prudente gradualismo de que hacen gala los gobernantes europeos cuando se enfrentan al dilema de compensar los avances de la unión económica y monetaria con un andamiaje constitucional de corte (y no sólo

${ }^{7}$ El hecho desencadenante fue la declaración unilateral de independencia de Croacia y Eslovenia los días 25 y 26 de junio, respectivamente. Ya en abril de 1992, el reconocimiento prematuro de BosniaHerzegovina por los Estados miembros de las Comunidades Europeas, un acto ejemplar de voluntarismo político que más adelante analizaremos, ha avivado y extendido el conflicto.

${ }^{8}$ Vid. Tratado de la Unión Europea (ed. de R. Alonso García), Madrid 1992, pp. 60-81 (Tít. VI del Tratado constitutivo de la Comunidad Europea: Política económica y monetaria) y 16-18 (Segunda Parte del mismo Tratado: Ciudadanía de la Unión). Obien Tratado de la Unión Europea y Tratados constitutivos de las Comunidades Europeas (ed. de A. Mangas Martín), Madrid 1992, pp. 219-242 y 170-172, respectivamente. 
de vocación o destino) auténticamente federal que permita superar las estructuras y procedimientos de un sistema político basado todavía en el compromiso entre cooperación e integración del que hoy sigue siendo tributaria la Comunidad Europea; porque después de Maastricht, seguimos pendientes de que se instaure en el seno de la C. E. un cierto equilibrio entre los poderes de los gobiernos de los Estados miembros y el protagonismo político que los ciudadanos y los pueblos soberanos deben poseer no sólo dentro de dichos Estados?.

\section{Una explicación errónea: el llamado «nuevo orden internacional»}

Todos asistimos perplejos, inquietos y esperanzados a la vez, a estos procesos normativos singulares porque no es fácil aprehender la compleja ingeniería sociohistórica que subyace en todos ellos. Se han adelantado explicaciones precipitadas e interesadas sobre los mismos. La coetánea agresión contra Kuwait y su inmediata anexión por parte de Irak en agosto de 1990, acto que obligó a una coalición de Estados bajo la autoridad del Consejo de Seguridad (a partir de ahora, C. de S.) de la Organización de las Naciones Unidas (a partir de ahora, O.N.U.) a una costosa guerra para liberar finalmente Kuwait el 28 de febrero de 1991, vino a demostrar que la conflictividad potencial encerrada, aunque hoy ya liberada con el fin de la guerra fría, en la tensión ideológica entre el Este y el Oeste, no era con mucho la única ni tampoco la más importante fuente de conflicto presente en la sociedad internacional (a partir de ahora, S.I.) contemporánea. Y, desde luego, el fin bienvenido de esta escisión política no presume pensar ni mucho menos en el «fin de la historia» ni permite soñar con el paraíso perdido bajo el sistema de gobierno de la democracia liberal, cuya formulación ideal, fundamentada en la aplicación de los principios gemelos de libertad e igualdad, sería ya imposible de mejorar en el futuro convirtiéndose así en punto final del desarrollo o progreso histórico de la Humanidad entendido al modo hegeliano ${ }^{10}$.

Otros han diagnosticado la aparición de un «nuevo orden internacional o mundial», caso del presidente estadounidense George Bush, creemos que sin mucha convicción y quizás con la intención casi exclusiva de rentabilizar políticamente la presunta victoria de las democracias pluralistas de libre mercado sobre los regímenes totalitarios de economía planificada. Operación de imagen que no parece le haya reportado ventaja ante un electorado procupado por la recesión económica y que

${ }^{9} \mathrm{Cf}$. Attina, F., Introducción al sistema político de la Comunidad Europea, trad. de A. Elvira, Madrid 1992, pp. 117-134; y la interpretación más integradora y optimista del TUE apuntada en el «Prólogo» de A. Mangas Martín (ed.), op. cit., pp. 22-27.

${ }^{10}$ Vid. la explicación propuesta, desde la filosofía de la historia, por F. Fukuyama, El fin de la historia y el último hombre, trad. de P. Elías, Barcelona 1992, en particular Partes III (pp. 205 y ss.) y IV (pp. 287 y ss.), que vuelve del revés la tesis marxista del advenimiento de la sociedad comunista al sostener que la historia nos conduce y dirige fatalmente hacia el reconocimiento universal del Estado liberal. 
muy probablemente lo saque de la Casa Blanca el próximo 3 de noviembre. La derrota electoral del propio Bush demostraría por sí misma hasta qué punto el electorado norteamericano no se considera tan satisfecho ni reconfortado con el triunfo del libre mercado como para ofrecerle sólo por eso otro mandato al actual Presidente.

Si pensamos con rigor, proponer la aparición de un «nuevo orden mundial», expresión a la que también recurren ahora profusa y alegremente los medios de comunicación ${ }^{11}$, supone afirmar, en otros términos, el nacimiento de una nueva forma o tipo histórico de sistema y - por ende- de ordenamiento internacional sustancialmente diferente del existente hasta 1990 y denominado comúnmente D. I. «contemporáneo» ${ }^{12} \cdot$ ¿Acaso hemos iniciado ya la era del D. I. —llamémosle asípostmoderno? Ni mucho menos. Un atento y desapasionado análisis de la actual realidad internacional nos muestra que no se da en absoluto la confluencia determinante del conjunto de factores o variables demográficas, económicas, tecnológicas, ambientales y propiamente políticas que por su propia naturaleza sean capaces de provocar un cambio sistémico y la superación del D. I. contemporáneo como forma o tipo histórico de ordenamiento surgido desde el fin de la Segunda Guerra Mundial y plenamente vigente desde $1970^{13}$.

Es cierto que se ha desvanecido la contradicción ideológica Este-Oeste, pero ni esta contradicción fue decisiva en el nacimiento del D. I. contemporáneo después de 1945, ni ha sido tampoco la razón principal que ayuda a explicar su desenvolvimiento hasta nuestros días ${ }^{14}$.

En efecto, la revolución soviética de 1917 y la constitución posterior del Bloque socialista formado sobre todo por Estados de la Europa del Este fue un fenómeno que cuestionó por un lado los principios políticos y económicos comunes en los que se fundaba el ordenamiento internacional clásico, ancladoen el cristianismo occidental y el liberalismo económico. Por otro lado, la Unión Soviética y el Bloque socialista

${ }^{11}$ Vid. per omnia diario El País, 17-VII-1991, p. 3.

${ }^{12}$ Entendemos por sistema internacional un conjunto de relaciones entre un determinado número de actores participantes (los Estados, las Organizaciones internacionales y las fuerzas transnacionales), comprendido en un determinado tipo de entorno o medio ecológico (nuestro planeta) y sometido a un determinado modo de regulación (el D. I.).: vid. Jiménez Piernas, C., «Reflexiones sobre el método del Derecho Internacional Público», epígrafe II, en Libro Homenaje al Profesor M. Díez de Velasco, 3 vols., Madrid 1993, Vol. I, en prensa.

${ }^{13}$ Como ha observado M. Merle refiriéndose al sistema internacional contemporáneo, y enseguida tendremos oportunidad de corroborar, «la eventualidad de mutaciones en el equilibrio de fuerzas o en la distribución del poder [en rigor, esto es lo que ha acontecido en el sistema al desaparecer el polo de poder formado por el Bloque socialista] tampoco afectaría obligatoriamente a la naturaleza del sistema. Este, tal como ha sido definido, puede experimentar transformaciones en su estructura y en sus modalidades de funcionamiento; pero ha alcanzado, en el curso de su evolución, unas características (globalidad, unicidad, cierre) que parecen inconmovibles...»: vid. Sociología de las relaciones internacionales, trad. española de la $4^{a}$ ed. francesa por R. Mesa, Madrid 1991, p. 514.

${ }^{14}$ Vid. Jiménez Piernas, C., «El concepto de Derecho Internacional Público (I)», en Díez de Velasco, M., Instituciones de Derecho Internacional Público, t. I, $9^{\mathrm{a}}$ ed., Madrid 1991, Cap. I, 57-79, pp. 60-62 y ss. 
representaron un nuevo polo de poder en las relaciones internacionales y en su ordenamiento, es decir introdujeron una modificiación importante en la organización política y jurídica del sistema internacional. Todo ello restó, en conjunto, estabilidad y homogeneidad al D. I. clásico, y propició lógicamente el juego de otros factores con vistas al cambio sistémico, en suma a la sustitución del D. I. clásico por el contemporáneo acaecida a partir de 1945.

Pero por sí sola, esta modificación estructural no hubiera conducido más que a ligeros cambios compensatorios en ciertos sectores del sistema internacional, sin modificar en ningún caso los rasgos sustanciales del D. I. clásico en cuanto ordenamiento genuinamente liberal, descentralizado y oligocrático. Es cierto que se diversificaron algo las relaciones de hegemonía y dependencia a causa de la constitución de un nuevo centro definido de poder; también se democratizó en algún grado el proceso de elaboración de las normas al sumarse a dicho proceso la práctica del grupo de Estados socialistas.

Ahora bien, en primer lugar el Bloque socialista defendió durante algún tiempo el recurso extremo a la fuerza y a la guerra como medio de extensión del socialismo real, o - si se quiere - como forma de expresión de la lucha de clases en el medio internacional; pero, precisamente, el recurso a la fuerza in genere ya lo consentía el D. I clásico como prueba de su carácter liberal. Por otro lado y en segundo lugar, el enfrentamiento entre Este y Oeste no facilitó la reducción o moderación del carácter descentralizado del D. I. clásico ante la dificultad de crear instituciones u órganos comunes que sirvieran de cauces de cooperación; no era precisamente el camino seguido con la creación de la O.T.A.N. y el Pacto de Varsovia ${ }^{15}$. En fin, y para terminar, el Bloque socialista significaba otro polo de poder que se justificaba por la previa existencia del polo primigenio, del formado por el grupo de Estados capitalistas, y se impuso desde un principio usar sus mismas armas (una descarada política de poder) en la confrontación ideológica con él; pero esa voluntad de poder se daba de bruces con cualquier intento serio de democratizar, socializar y humanizar el D. I., tal como entendemos que exigía la superación del D. I. clásico, esto es el cambio sistémico.

En rigor, el D. I. contemporáneo surge con cierta nitidez como producto del juego de otros factores, ayudados —es cierto— por el fenómeno recién comentado. Porque el Bloque socialista fue, por ejemplo, decidido partidario y patrocinador del gran proceso descolonizador dentro y fuera de la O.N.U. Y ese gran proceso descolonizador, la segunda gran revolución colonial tras la protagonizada a fines del XVIII y principios del XIX por las antiguas colonias americanas, es sin género de

\footnotetext{
${ }^{15}$ Como ha manifestado certeramente el Prof. J. A. Pastor Ridruejo, en su Curso de Derecho Internacional Público y Organizaciones Internacionales, $4^{\mathrm{a}}$ ed., Madrid 1992, p. 80: «...la escisión EsteOeste trajo como secuela una acentuación del regionalismo internacional; además de la cooperación militar con fines defensivos - OTAN, Pacto de Varsovia-, es claro que en otros terrenos los Estados preferían cooperar con los que les eran afines en concepciones culturales, políticas, económicas y sociales.»
} 
duda uno de los grandes factores de cambio del D. I. clásico, ya que va a producir una extraordinaria ampliación de la S. I., convertida por fin en S. I. universal o mundial. La S. I. clásica previa a la Primera Guerra Mundial, reducida y homogénea, pierde paulatinamente en el camino que la lleva hasta los años cincuenta de este siglo, primero su homogeneidad ideológica a causa de la revolución soviética y luego su homogeneidad cultural a causa de la incorporación a la vida de relación internacional, tras la Segunda Guerra Mundial, de gran número de Estados africanos y asiáticos. Precisamente esta masiva incorporación explica la pérdida de su carácter pequeño o reducido y su conversión radical en una S. I. universal o mundial, además de pluricultural ${ }^{16}$. La vuelta a una cierta homogeneidad ideológica no altera en absoluto la nota básica de la universalidad pluricultural de la S.I. contemporánea como rasgo distintivo de su estructura sociohistórica o material actual.

Pero hemos dicho antes que la contradicción ideológica Este-Oeste no sólo no fue decisiva en el nacimiento del D. I. contemporáneo, sino que tampoco ha constituido la razón principal que ayude a explicar su desenvolvimiento hasta nuestros días. En efecto, la S. I. contemporánea se define ante todo, además de por su carácter universal y pluricultural, por las notas de su complejidad, dinamismo, escasa integración, interdependencia y - por encima de todas ellas - su heterogeneidad. Es heterogénea ante todo por la desmesurada desigualdad económica entre Estados desarrollados y Estados en desarrollo, que divide de hecho a éstos en dos mundos bien diferentes (el Centro y la Periferia, o el Norte y el Sur, según se prefiera), hecho cuyo origen remoto podría ser la revolución industrial de Occidente favorecida por el proceso de acaparación y explotación colonial, pero que hoy se concreta en tres factores determinantes, a saber, la posesión del capital y la teconología, el control de las instituciones financieras internacionales y una relación desigual en los intercambios comerciales, siempre a favor del mundo desarrollado.

El mar Mediterráneo, por ejemplo, es una auténtica línea de fractura entre el Norte y el Sur tanto por los conflictos hoy abiertos en su área de influencia (Argelia, Palestina, Líbano, Chipre, Yugoslavia y Sahara occidental), como por la escisión demográfica, económica y tecnológica que padecen sus cuencas meridional y septentrional, sin olvidar las diferencias políticas y culturales entre ellas (democracias pluralistas y cultura cristiana occcidental en el Norte; regímenes dictatoriales y autocráticos y cultura musulmana en el Sur). España hace precisamente de limes entre estos dos mundos, una situación geográfica delicada que exige una reflexión y respuesta adecuadas de nuestra política exterior. El problema, por ejemplo, de la inmigración ilegal o clandestina desde el otro lado del estrecho de Gibraltar debe analizarse en este amplio contexto y no de forma aislada.

\footnotetext{
${ }^{16}$ Sirva como testimonio reciente del parecer unánime de la doctrina a este respecto el estudio de $\mathrm{C}$. Gutiérrez Espada, «Sobre las funciones, fines y naturaleza del Derecho Internacional Público contemporáneo», en Funciones y fines del Derecho. Homenaje al Profesor Mariano Hurtado Bautista, Univ. de Murcia 1992, 53-82, pp. 56-61.
} 
Tan irresponsables y demagógicos nos parecen los llamamientos en favor del cierre de nuestras fronteras a la inmigración norteafricana, como los que se hacen pidiendo una política de puertas abiertas para esa y cualquier otra inmigración. La Administración española ha reaccionado muy tarde ante este problema y ha arbitrado hasta ahora soluciones técnicas y policiales. Debe haberlas de otra clase. Nos inclinamos por la fórmula clásica de establecer cupos o contingentes anuales de acuerdo con la capacidad de absorción de nuestro mercado laboral, teniendo en cuenta los intereses de nuestro interlocutor principal en este tema (Marruecos), de forma que la inmigración se produzca ordenadamente y en beneficio mutuo ${ }^{17}$. Es imprescindible contar con la colaboración de Marruecos para evitar la inmigración salvaje a España, tal y como se ha venido produciendo en los últimos meses con la anuencia de las autoridades marroquíes. Esta situación ha permitido la aparición de mafias y la explotación por desaprensivos tanto del tráfico clandestino de inmigrantes como de una mano de obra ilegal y barata.

Si seguimos nuestro discurso, la S. I. contemporánea es también heterogénea por la evidente desigualdad del poder político entre las grandes potencias y el resto de Estados. Esta escisión es en gran medida complemento y consecuencia de la escisión económica recién comentada, de la que viene a ser una especie de reducción o simplificación ratione personae, ya que todas las grandes potencias son Estados desarrollados. La actual Federación de Rusia y la República Popular China, aunque ocupan puestos permanentes en el Consejo de Seguridad, se encuentran a mitad de camino entre ambos mundos, el desarrollado y el subdesarrollado.

Pues bien, la S. I. contemporánea, tras el derrumbamiento del Bloque socialista y el fin de la tensión Este-Oeste, sigue siendo - por supuesto- descentralizada, básicamente interestatal y sólo parcialmente organizada, y si atendemos especialmente a la nota de su heterogeneidad, sigue estando caracterizada por la escisión económica entre Centro y Periferia o Norte y Sur, y por la escisión política entre las grandes potencias y el resto de Estados. En este sentido, el aumento del número de Estados producido por la desintegración del Bloque socialista aboga precisamente por la consolidación de los caracteres de la descentralización y escasa institucionalización de la S. I. contemporánea. Es, pues, el dato de la gran desigualdad entre los Estados que evidencian estas contradicciones el obligado punto de partida de cualquier reflexión sobre la estructura actual de la S. I. ${ }^{18}$, y el único modo racional de tomar conciencia de los peligros que verdaderamente acechan a la estabilidad del D. I. contemporáneo, que sólo perdurará si logra resolver esta escisión trascendental entre Estados ricos (muy pocos) y pobres (la inmensa mayoría) que hoy determina la vida de relación internacional.

\footnotetext{
${ }^{17}$ Esta parece ser la política que ha decidido seguir el Gobierno tras el preocupante incremento de conductas xenófobas en nuestro país: vid. diario El País, 21-XII-1992, p. 17.

${ }^{18}$ Rodríguez Carrión, A. J., Lecciones de Derecho Internacional Público, $2^{a}$ ed., Madrid 1990, pp. 61 y $66-74$.
} 


\section{Análisis de la nueva situación, con especial referencia a España}

La desaparición de la contradicción entre el Este y el Oeste, aunque no justifique en absoluto afirmar la aparición de un nuevo orden mundial, ha producido desde luego ciertas consecuencias dentro del sistema internacional, porque tampoco sería riguroso sostener que no han sucedido acontecimientos importantes en estos últimos años. A continuación comentaremos algunas de esas consecuencias, las que estimamos más llamativas. No sin antes advertir que en estos acontecimientos España ha desempeñado y está desempeñando cierto papel, el que le corresponde _como potencia media con cierta proyección mediterránea y sobre todo iberoamericana. Este hecho, el que España desempeñe algún papel en las relaciones internacionales, es sin duda un fenómeno importante para nosotros tras el larguísimo período de ausencia y de ostracismo de los foros internacionales que nuestro país vivió desde el fin de la Guerra de la Independencia con el ridículo papel desempeñado en el Congreso de Viena celebrado en 1815 . Siglo y medio de silencio y servidumbres que ha roto felizmente nuestra Constitución de 1978 y los gobiernos democráticos que se han sucedido desde entonces ${ }^{19}$.

Qué duda cabe que la desaparición de un centro o polo de poder y la desintegración de la potencia hegemónica que lo controlaba, junto a la pérdida de su condición de superpotencia (la Federación de Rusia no es la antigua Unión Soviética aunque ocupe su escaño en el C. de S. de la O.N.U.), son hechos que pueden propiciar ciertos intentos hegemónicos por parte de la otra superpotencia o del otro polo de poder supervivientes (Estados Unidos y el Bloque occidental, respectivamente).

No ha sido ese el caso de la guerra contra Irak para liberar Kuwait, que se decidió y llevó a cabo aún con la Unión Soviética ocupando su puesto permanente en el C. de S. ${ }^{20}$. Este conflicto concitó una rara unanimidad porque finalizada ya la guerra fría (fin que, advirtámoslo, es anterior en muy poco tiempo, pero anterior, a la desintegración del Bloque socialista y a la desaparición de la contradicción EsteOeste), era más fácil el acuerdo en el seno del C. de S. para hacer frente a una violación tabú del D. I. contemporáneo: la guerra de agresión con el objetivo de eliminar y anexionar un Estado soberano y miembro de pleno derecho de la O.N.U.,

\footnotetext{
${ }^{19}$ España viene colaborando desde 1988 con cierto éxito en el encauzamiento y solución de algunos conflictos internos en América (Nicaragua, El Salvador) y Africa (Namibia, Angola), aportando medios financieros y humanos (cascos azules) a la O.N.U. para el desarrollo de estas operaciones. Fuerzas españolas participaron también en 1991 en la intervención humanitaria autorizada por el C. de S. para proteger a los refugiados kurdos en el norte de Irak tras la derrota militar de su levantamiento contra el régimen de Sadam Husein en marzo de 1991. Cabe esperar un aumento de esta clase de acciones colectivas para preservar la paz y la seguridad internacional, en las que España deberá afrontar su parte alícuota de las nuevas responsabilidades que el fin de la guerra fría y la pérdida de liderazgo de las dos superpotencias militares ha trasladado fundamentalmente a la sociedad internacional organizada, en especial a la O.N.U.

${ }^{20}$ Vid. sobre la legalidad del empleo de la fuerza contra Irak, A. Datis Quecedo, «El uso de la fuerza armada en el Golfo: una justificación jurídica», en REDI,col. XLIII (1991), 109-116.
} 
acto ilícito sin precedentes desde el fin de la Segunda Guerra Mundial que mereció una repulsa generalizada basada en muchos casos en el miedo razonable de los Estados pequeños a que se abriera de nuevo la veda para atropellos de este tipo. Con esta reacción, el D. I. contemporáneo confirma que el D. I. clásico (el que legitimó, por ejemplo, los sucesivos repartos de Polonia) está muerto y bien muerto.

En este conflicto, el Gobierno español se limitó a cumplir sus compromisos internacionales, con el mayor respeto a nuestros preceptor constitucionales, en su triple condición de Estado miembro de la O.N.U., de la Organización del Tratado del Atlántico Norte (O.T.A.N.)) y de las Comunidades Europeas; su aportación, como es sabido, se tradujo en un importante apoyo logístico al esfuerzo de guerra aliado; además, participó con fuerzas navales en la vigilancia del embargo comercial decretado contra Irak por la Resolución 665 (1990) del C. de S. ${ }^{21}$.

Creemos que la conducta de España durante este conflicto repercutió positivamente en nuestras relaciones internacionales al otorgarnos una credibilidad de la que hasta hace poco carecíamos. Este conflicto sirvió para demostrar que, después de una aislamiento secular, España se incorporaba plenamente al grupo de las democracias occidentales y cumplía con sus obligaciones convencionales cundo era el caso. Por otra parte, el Gobierno español se preocupó de recordar en tan señalada ocasión su posición tradicional sobre el problema palestino, satisfaciendo moralmente las justas reivindicaciones de los Estados árabes y de la Organización para la Liberación de Palestina (O.L.P.), a pesar del triste y airado papel jugado por esta Organización al defender la agresión iraquí contra Kuwait.

La oposición contra la participación española en el conflicto, participación por otro lado poco o nada arriesgada, trajo a nuestra memoria ecos del más rancio franquismo, cuando sufríamos aislados los rigores de una dictadura y se nos contaba que tanto la O.N.U. como el D.I. eran un invento de las democracias liberales entre cuyos objetivos se incluía obviamente perturbar nuestra idílica paz con absurdas pretensiones, como la de que se respetaran los derechos humanos en nuestro país. Desafortunadamente, el secretismo de nuestro Gobierno y su falta de confianza en la madurez democrática de la opinión pública española para comprender las razones de nuestra participación en el conflicto, contribuyeron al fracaso de su política informativa a este respecto, dando así alas a los reflejos aldeanos aún enraizados en sectores minoritarios de nuestra sociedad, que parecen desconocer absolutamente la relación de interdependencia en que nos situa nuestra completa incorporación a la economía de libre mercado desde el ingreso en las Comunidades Europeas el 1 de enero de 1986. Por fuerza nos tiene que preocupar lo que ocurra en el Golfo Pérsico si nuestra economía recibe de esa región buena parte del crudo que consume. Esos sectores minoritarios acusaron al Gobierno de servilismo con los intereses de las

${ }^{21}$ Vid. «Práctica española de Derecho Internacional Público», en REDI, vol. XLIII (1991), pp. $132-$ 152. Y VV. AA., Nota sobre «El Derecho Internacional y la crisis deI Golfo», en REDI, vol. XLII (1990), 673-696, en particular pp. 679-684 y 693-696 para las conductas seguidas por la Comunidad Europea y España. 
grandes potencias occidentales y sobre todo de los Estados Unidos; para esos sectores no parece haber término medio entre la nostalgia por el imperio y el aislacionismo puro y duro. España no es una gran potencia y debe aceptar con humildad e inteligencia el papel posible que la propia dinámica de las relaciones internacionales atribuye en nuestro días a una potencia media o regional.

Si volvemos a nuestra argumentación, tampoco cabe considerar como un rebrote hegemónico la última intervención militar norteamericana en Panamá, en diciembre de 1989. Porque Estados Unidos, aduciendo distintas excusas, ha intervenido decisivamente en los asuntos internos de varios Estados de su patio trasero (léase Caribe y Centroamérica) en plena guerra fría y en el apogeo del enfrentamiento ideológico y militar interbloques, poniendo de manifiesto su tradicional hegemonía regional en ese continente. Recordemos la grave intervención militar de 1966 en la República Dominicana. España, por su parte, votó a favor de la Res. 44/240 de la A.G. de la O.N.U., aprobada por amplia mayoría, que condenó sin paliativos la intervención militar norteamericana en Panamá, siendo el único Estado de las Comunidades Europeas que lo hizo, ya que Irlanda y Grecia se abstuvieron y el resto votó en contra. Las autoridades españolas se expresaron claramente al respecto, sosteniendo que la intervención violaba la Carta de la O.N.U. y que el Gobierno español siempre se había mostrado contrario a ella ${ }^{22}$. La posición española no tuvo ningún eco entre sus socios comunitarios, lo que demuestra como enseguida reiteraremos al tratar el asunto yugoslavo- las dificultades y miserias de la llamada Cooperación Política Europea instaurada por el Acta Unica de 1986 y que el Tratado de la Unión Europea pretende ampliar y potenciar ${ }^{23}$.

De igual forma, tampoco cabe achacar a nuevas veleidades hegemónicas el conflicto yugoslavo, que asola desde julio de 1991 la antigua República Federativa de Yugoslavia ${ }^{24}$. Recordemos que ya desde 1990 y al calor de la disolución rápida y general de los Partidos Comunistas en la Europa del Este, había quebrado en Yugoslavia el orden constitucional ficticio creado por el Mariscal Tito tras la Segunda Guerra Mundial, articulado como es sabido en torno a dos grandes ejes, el centralismo democrático y el aparato del Partido Comunista, al margen por tanto del propio aparato del Estado convertido así en un armazón inoperante. La desintegración de la antigua Yugoslavia responde, desde luego, a una crisis similar a las que se han dado en la antigua Unión Soviética y en la antigua Checoslovaquia, a saber, la desarticulación del centralismo democrático y del aparato comunista deja en evidencia unas estructuras estatales artificiales e incapaces de encauzar nuevas formas de convivencia política. El caso yugoslavo sirve de paradigma.

${ }^{22}$ Vid. «Práctica española de Derecho Internacional Público», en REDI, vol. XLII (1990), pp. 530531.

${ }^{23}$ Vid. Tratado de Roma. Acta Unica, Madrid 1987 (ed. de Cívitas), Tít. III del Acta Unica en pp. 124127. Y Tít. V del Tratado de la Unión Europea en R. Alonso García (ed.), op. cit., pp. 183-188.

${ }^{24}$ Vid. información reciente y de interés sobre este conflicto en diario El País, 10-VII-1991, p. 4; 4-IX-91, p. 6; 15-VIII-1992, pp. 3-4 y 12; 18-VIII-92, p. 4; 21-VIII-92, p. 4; 26-VIII-92, pp. 3-5; y 29-VIII-92, p. 3. 
En efecto, el conjunto de pueblos eslavos instalados en esas tierras (los servios de religión ortodoxa, los croatas de religión católica y los bosnios de religión musulmana) han vuelto al estado de naturaleza desencadenándose desde el año pasado una cruel guerra civil cuyo final no se vislumbra pero que parece conducir a la consolidación de Servia y Croacia como los Estados sucesores principales de la antigua Yugoslavia, después de consumada en estos últimos meses la división de facto de la antigua República de Bosnia-Herzegovina a costa del sacrificio de la mayoría musulmana, cantonalizada en algunas zonas o reservas de esa República, para evitar así la presencia de minorías de bosnios musulmanes en las regiones controladas por Croacia y Servia. Previamente, ya en 1991, Servia consiguió controlar de facto importantes zonas fronterizas de la República de Croacia donde eran mayoritarios los servios aduciendo razones idénticas, la revisión de las fronteras para hacer coincidir cada República con la presencia casi exclusiva del pueblo que la constituye. No olvidemos que antes de iniciarse el conflicto residían en Bosnia cerca de millón y medio de servios y en Croacia más de medio millón, que no han recibido nunca garantías claras sobre el trato debido a esta minoría por parte de Croacia.

Una guerra civil manifiesta ante todo el fracaso del orden constitucional previo a su estallido, no afecta ni cuestiona en principio el ordenamiento internacional vigente, que sólo desempeña un papel menor en estos conflictos bélicos de carácter no internacional. Ese papel se circunscribe esencialmente a conseguir el respeto del Derecho Internacional Humanitario durante las hostilidades ${ }^{25}$, tarea harto difícil por los agravios y los odios históricos que trufan esta clase de conflictos, además de evitar la injerencia unilateral e interesada de otros Estados en el conflicto. Este segundo objetivo, no violar el principio estructural que prohibe la injerencia en los asuntos internos de otro Estado (en este caso, la antigua República Federativa de Yugoslavia), se había logrado a duras penas hasta que se produjo el desafortunado reconocimiento prematuro de Bosnia que pasamos a comentar de inmediato.

Los problemas a este respecto han provenido sobre todo de la diplomacia de la Comunidad Europea, que ha sido desde el inicio del proceso de desintegración de Yugoslavia errática y errónea. La C.E. favoreció en un principio el mantenimiento de la unidad yugoslava, se inhibió luego al producirse su desmembración de facto, para más tarde precipitarse bastante al reconocer como Estado soberano a Croacia el 15 de enero de 1992, y poco después precipitarse demasiado al reconocer como Estado soberano a Bosnia el 6 de abril de 1992. No tenemos dudas acerca de que el reconocimiento de Bosnia por parte de los Estados miembros de la C.E. fue prematuro y contrario al D. I., ya que cuando se produjo dicho reconocimiento no se cumplía la condición —exigida por el D. I. consuetudinario-del control efectivo

${ }^{25}$ Vid. e. g. Comité Internacional de la Cruz Roja, Informe de actividad-1991, Ginebra, 1992, pp. 8793. Y para 1992, la documentación de la Revista Internacional de la Cruz Roja, núm. 113 (septiembreoctubre, 1992), pp. 515-520. 
de una porción significativa del territorio y de la población en cuestión por parte de las autoridades bosnias ${ }^{26}$. Los resultados no han podido ser más frustrantes además de peligrosos, porque se ha sentado un mal precedente jurídico, cabe pensar de buena fe que con el fin de conseguir una importante ganancia política, evitar la guerra civil en Bosnia al hacerla presuntamente inoperante en virtud del reconocimiento adelantado del ente soberano que la guerra pretendería elucidar por la vía de la fuerza, sin pensar que la guerra podría tener otros objetivos, a saber, la revisión de fronteras y la «limpieza étnica», objetivos que al mismo tiempo — como la tozudez de los hechos viene demostrando- cuestionan de raiz la propia existencia del Estado bosnio.

El reconocimiento contrario a derecho de Bosnia se debió a la fuerte presión de la nueva Alemania, que ya ha hecho sentir su peso virtualmente hegemónico en este importante problema al convertirse en valedora de Eslovenia y Croacia (antiguos territorios del Imperio Austro-Húngaro) ante la C. E., arrastrando al resto de sus socios comunitarios para salvar la cooperación europea en materia de política exterior establecida en el Acta Unica. La República Federal de Alemania ha impulsado desde la C. E. una política de cierta injerencia en los asuntos internos de la antigua Yugoslavia y ha sido además ferviente partidaria de intervenir militarmente en el conflicto, pero de que intervinieran otros porque la Ley Fundamental prohibe el envío de soldados fuera de territorio alemán.

En cuanto a España, nuestro Gobierno se ha comprometido a enviar y sufragar los gastos de unos setecientos soldados dentro del contingente de cascos azules que protegerán el suministro de ayuda humanitaria a Bosnia-Herzegovina en virtud de la Resolución 770 (1992) del C. de S. de la O.N.U. Si bien el Gobierno español pretende ahora que la C. E. o la propia Alemania se subroguen en los cuatro mil millones de pesetas que cuesta esta misión para una duración prevista de seis meses. Es cierto que nuestro Gobierno se encuentra empeñado en una interesante batalla diplomática por conseguir uno de los puestos no permanentes en el C. de S. de la O.N.U. para el próximo bienio 1993-94; es, por tanto, lógico que coopere decididamente con el C. de S. en esta operación humanitaria ${ }^{27}$. Es cierto también que el debate sobre la cohesión social, su coste y reparto, no ha terminado en el seno de la C. E., y que Alemania tiene mucho que decir en este tema ${ }^{28}$. No obstante, esta cooperación humanitaria encierra muchos más riesgos que nuestra cómoda participación en la guerra contra Irak. Además, en este conflicto, nuestro Gobierno ha actuado algo

\footnotetext{
${ }^{26}$ Vid. per omnia Brownlie, I., Principles of Public International Law, 4th ed., Oxford 1990, pp. $72-$ 73 y $92-93$.

${ }^{27}$ Vid. diario El País, 13-VIII-1992, p. 12; 4-IX-92, p. 17; y 26-IX-92, p.4. España logró finalmente su objetivo el 27 de octubre de 1992 al ser votada por ciento dieciocho Estados miembros, obteniendo en la primera vuelta dos votos más de la mayoría de dos tercios de los miembros presentes y votantes exigida por el art. 18 de la Carta de la O.N.U. para ocupar un puesto no permanente en el C. de S.

${ }^{28}$ Como es sabido, el problema se cerró satisfactoriamente para España, gracias sobre todo a la buena disposición alemana, en la Cumbre de Edimburgo celebrada los días 12 y 13 de diciembre de 1992.
} 
forzado por los compromisos históricos y la vocación intervencionista de la nueva Alemania, y se ha comprometido en un problema de hondo calado político al avalar de algún modo con su participación en unos reconocimientos muy controvertidos la secesión por la fuerza de un Estado europeo ${ }^{29}$.

En cambio, sí hay dos buenos y muy recientes ejemplos de esos temidos rebrotes hegemónicos, protagonizados casi en exclusiva por Estados Unidos. Se trata, a nuestro entender, de dos buenos precedentes porque no hay en ellos una simple y episódica violación, mal justificada, de alguna norma internacional. Más bien hay en ellos ya un intento de reconducir y forzar la buena interpretación del D. I. vigente (el primer ejemplo), llevándolo por derroteros que generalicen los abusos o excesos en su aplicación en favor siempre de los Estados más poderosos (en este caso, los miembros permanentes del C. de S.), ya una impugnación en regla de algunas normas internacionales fundamentales hoy en vigor que ha sido justificada - esto es lo más grave- por una sentencia del Tribunal Supremo norteamericano (el segundo ejemplo), que puede quizás encerrar un designio de modificar los contenidos de conducta de esas normas a fin de adecuarlos formalmente a la realidad de la supremacía de ciertos Estados (concretada, en este caso, en la voluntad norteamericana de perseguir y reprimir el narcotráfico fuera de sus fronteras e incluso en el territorio de otros Estados).

El primer ejemplo lo ofrecen las Resoluciones 731 (1992) y 748 (1992) del C. de S., auspiciadas por Estados Unidos, Reino Unido y Francia ${ }^{30}$. En la primera Resolución se exigió al Gobierno libio la adopción de ciertas medidas, y en la segunda se le impusieron sanciones por el incumplimiento de la primera, ya que el Gobierno libio se ha negado hasta ahora a conceder la extradición de dos de sus nacionales para ser juzgados en el Reino Unido o en Estados Unidos como presuntos autores del desastre aéreo de Lockerbie (la destrucción el 21 de diciembre de 1988 de una aeronave de Pan Am en vuelo sobre este pueblo escocés), exigencia que era la causa principal de la primera Resolución. Conforme al D. I. general, la concesión de una extradición es decisión soberana del Estado requerido, que no está obligado a concederla, es decir, que es libre de rehusarla sin que de ello se derive en principio ninguna consecuencia ni para el Estado requerido ni para el particular o los

${ }^{29}$ Vid. en este sentido «Práctica española de Derecho Internacional Público», en REDI, vol. XLIII (1991), pp. 444-445; y vol. XLIV (1992), pp. 118-120. Así como la nota de documentación de J. Rodríguez Ponga y Salamanca sobre «La Comisión de arbitraje de la Comunidad Europea sobre Yugoslavia», en REDI, vol. XLIV (1992), pp. 252-259.

${ }^{30}$ Vid. sobre este tema Application Instituting Proceedings Submitted by the Government of the Socialist People's Libyan ArabJamahiriya, 3 March 1992, 10pp.; y Requestfor the Indication of Provisional Measures of Protection Submitted by the Government of the Socialist People's Libyan Arab Jamahiriya, 3 March 1992, 4 pp. Además de International Court of Justice, Case Concerning Questions of Interpretation and Application of the 1971 Montreal Convention Arising from the Aerial Incident at Lockerbie (Libyan Arab Jamahiriya v. United Kingdom), Request for the Indication of Provisional Measures, Order 14 April 1992, párs. 29-43; y Joint Declaration to the Order of the Court by the Judges Evensen, Tarassov, Guillaume and Aguilar Mawdsley, párs. 1-4, que explicita mejor que la propia Orden de 14 de abril de 1992 el sentir de la mayoría de la Corte sobre este Caso. 
particulares afectados por la solicitud de extradición. Por su parte, los arts. 7, 5 y 8 de la Convención de Montreal de 23 de septiembre de 1971 sobre la represión de actos ilícitos contra la seguridad de la aviación civil, de la que son partes Estados Unidos, Libia y el Reino Unido, facilitan sin duda posibles extradiciones pero no crean obligaciones a este respecto para los Estados partes, salvo la de proceder penalmente sin admitir excepciones contra los presuntos culpables (sean o no nacionales) detenidos en su territorio, si no se accede a su extradición a otro Estado parte.

Pues bien, a pesar del D. I. consuetudinario y convencional vigente aplicable a este asunto, el C. de S. ha prescindido del mismo en las dos Resoluciones citadas, adoptadas en el marco de las competencias que le otorga el Capítulo VII de la Carta de la O.N.U. con el fin de preservar la paz y la seguridad internacional combatiendo - en este asunto - el terrorismo internacional, y ha evitado incluso la intervención de la Corte Internacional de Justicia (a partir de ahora, C. I. J.) ante la demanda presentada por Libia el 3 de marzo de 1992 y su petición de medidas provisionales en su conflicto con el Reino Unido sobre la interpretación y aplicación de la citada Convención de Montreal, ya que adoptó la Resolución 748 (1992) que contenía sanciones contra Libia por el incumplimiento de la Resolución 731 tres días después de que finalizara el procedimiento oral ante la C.I.J. y apenas catorce días antes de que la C.I.J. se pronunciara sobre la petición libia, que precisamente pretendía evitar tales sanciones hasta que la C.I.J. resolviera sobre el fondo del asunto, esto es, la controversia jurídica sobre la interpretación y aplicación de la Convención de Montreal.

Parece evidente que los gobiernos de Estados Unidos y el Reino Unido, al patrocinar estas Resoluciones, han usurpado el derecho y la facultad de la C.I.J. para decidir sobre la demanda y petición de medidas provisionales hecha por Libia, violando la letra y el espíritu del art. 92 de la Carta de la O.N.U. y el Estatuto de la C.I.J., que es parte integrante de la $\mathrm{Carta}^{31}$; $\mathrm{y}$ han provocado que el C. de S. actue ultra vires eludiendo cualquier control de la legalidad de sus decisiones mediante el recurso a una política de hechos consumados frente a la C.I.J., que no tuvo otra alternativa que alegar el art. 103 de la Carta de la O.N.U. (por el que las obligaciones contraidas en virtud de la Carta prevalecen sobre cualesquiera otras obligaciones convencionales), para justificar muy forzadamente la preferencia de las Resoluciones citadas sobre el D. I. general y convencional en la materia, y negarse así a dictar las medidas provisionales pedidas por el Gobierno libio.

Los indicios o las evidencias sobre la implicación del Gobierno libio en actividades terroristas no eximen del escrupuloso respeto del D. I. en vigor, cuya clave de bóveda sigue siendo el principio de la soberanía de los Estados, cualquiera

${ }^{31} \mathrm{E} 1$ art. 92 de la Carta reza como sigue: «La Corte Internacional de Justicia será el órgano judicial principal de las Naciones Unidas; funcionará de conformidad con el Estatuto anexo, que está basado en el de la Corte permanente de Justicia Internacional, y que forma parte integrante de esta Carta». 
que sea su adscripción geográfica y poder. En cuanto a España, nuestro Gobierno se ha limitado hasta ahora a aplicar las sanciones del C. de S., suspendiendo indefinidamente todo tráfico aéreo con $\mathrm{Libia}^{32}$.

El segundo ejemplo no es otro que la Sentencia de 15 de junio de 1992, dictada por el Tribunal Supremo norteamericano, en el Caso Álvarez Machaín ${ }^{33}$, que pone en evidencia el socavamiento del prestigio de esa institución judicial, inmersa ya desde la pasada década y sobre todo desde 1990 en un radical cambio de orientación marcadamente conservador de su jurisprudencia en temas tan sensibles como la protección de los derechos fundamentales de la persona, que es consecuencia del relevo generacional sufrido en su composición durante la administración de los dos últimos presidentes republicanos ${ }^{34}$.

Constan como hechos probados en la citada Sentencia que el nacional mejicano Humberto Alvarez Machaín fue secuestrado en territorio mejicano el día 2 de abril de 1990 y llevado a territorio norteamericano, correspondiendo la responsabilidad de ese secuestro a agentes de la Drug Enforcement Administration (DEA), agencia federal que se ocupa de la lucha contra el tráfico de estupefacientes. La DEA acusaba al secuestrado de haber participado en el secuestro y asesinato en Méjico de su agente Enrique Camarena Salazar, de nacionalidad norteamericana. Y que el Gobierno norteamericano, con pleno conocimiento de los hechos, no hizo ni ha hecho nada hasta ahora por remediarlos devolviendo al nacional mejicano a su país ${ }^{35}$.

A solicitud del Consejo Permanente de la Organización de Estados Americanos por Resolución CP/RES. 586 (909/92), de 15 de julio, el Comité Jurídico Interamericano (a partir de ahora, C. J. I.) emitió por nueve votos a favor y una abstención un dictamen de 15 de agosto de $1992^{36}$ pronunciándose en términos rotundos sobre la no conformidad de la citada Sentencia con el D. I. en vigor.

En opinión del C. J. I., el T. S. norteamericano, al afirmar la jurisdicción de los Estados Unidos para juzgar penalmente al nacional mejicano secuestrado de su país de origen en aplicación del discutido adagio male captus bene detentus, desconoce la obligación jurídica internacional que incumbe al Gobierno norteamericano, como

\footnotetext{
${ }^{32}$ Pero nuestra recientísima incorporación al C. de S. (vid. supra nota 27), obligará al Gobierno a definirse y pronunciarse sobre este y otros muchos conflictos en los dos próximos años.

${ }^{33}$ Vid. el texto de la Sentencia (United States, Petitioner v. Humberto Alvarez-Machain, June 15, 1992) en The United States Law Week, vol. 60, no 49, June 16 1992, pp. 4523-4532.

${ }^{34}$ Vid. Garro, A. M., «Algunas reflexiones sobre la Corte Suprema de los Estados Unidos en su actual composición y el rol institucional de la Corte», en Revista Española de Derecho Constitucional, núm 35 (Mayo-Agosto 1992), 85-95, passim.

${ }^{35}$ Vid. un repaso de la práctica internacional de interés para este Caso, si bien referida normalmente a secuestros de nacionales (Alvarez Machaín no es nacional norteamericano) perpetrados en el territorio de otro Estado, en Jiménez Piernas, C., «El particular ante el Derecho de la responsabilidad internacional: los problemas previos del standard mínimo y la protección diplomática», en Cursos de Derecho Internacional de Vitoria-Gasteiz, 1987, 65-116, pp. 90-94.

${ }^{36}$ Vid. el texto del dictamen emitido por el Comité Jurídico Interamericano en CJI/RES. II. 15/92, Opinión jurídica sobre la Sentencia de la Suprema Corte de Justicia de los Estados Unidos de América, $7 \mathrm{pp}$.
} 
responsable último del secuestro, de repatriarlo a su país, sin duda la mejor forma de reparar (restitutio in integrum) las consecuencias de la violación de la soberanía territorial de Méjico. Al sostener la tesis de que puede juzgarse a personas secuestradas por medio de la acción o conducta de agentes o funcionarios gubernamentales en el territorio de otros Estados a menos que ello esté expresamente prohibido por un tratado vigente con el Estado de que se trate, el T. S. norteamericano desconoce el principio estructural del D. I. que exige el respeto de la soberanía territorial del Estado; principio que forzosamente debe inspirar cualquier interpretación del Tratado de Extradición vigente entre Estados Unidos y Méjico cuyo objeto y fin no era precisamente facilitar el secuestro por la fueza de personas, sino regular jurídicamente la cooperación en materia de extradición entre ambos Estados, razones por las que tanto el Tribunal Federal de Distrito - en primera instanciacomo el Tribunal de Apelaciones desecharon las acusaciones contra el nacional mejicano y ordenaron su repatriación, fallos que fueron casados por la Sentencia del T. S. Es evidente, en fin, como recuerda el C. J. I., que los criterios sentados por el T. S. norteamericano, llevados hasta sus últimas consecuencias, atribuirían a cada Estado la facultad de violar caprichosa e impunemente tanto la soberanía territorial de los demás Estados, como los derechos humanos del o de los secuestrados, sin duda conculcados por el secuestro.

España ha apoyado, en la última Cumbre Iberoamericana de Jefes de Estado y de Gobierno celebrada en Madrid los días 23 y 24 de julio de este mismo año ${ }^{37}$, que el conflicto jurídico surgido con este motivo entre los Gobiernos mejicano y estadounidense pueda dilucidarse mediante una solicitud de dictamen a la C. I. J. ${ }^{38}$. Aunque estimamos que hubiera sido más práctico y menos arriesgado, además de muy ejemplar desde un punto de vista estrictamente jurídico, que los Estados miembros de la C. E. , en el marco de la Cooperación Política Europea, manifestaran formalmente al Gobierno norteamerciano su apoyo a la tesis del Gobierno mejicano y del C.J.I. y su oposición al contenido y consecuencias de esa decisión judicial; reacción que, naturalmente, no se ha producido.

\footnotetext{
${ }^{37}$ Sobre la historia, los propósitos, los principios y la estructura de las Cumbres Iberoamericanas, vid. Fernández-Shaw Baldasano, F., Del descubrimiento al encuentro: las Cumbres Iberoamericanas, Comunicación al XVII Congreso del IHLADI celebrado en Cáceres del 13 al 19 de septiembre de 1992, Madrid (Secretaría del IHLADI) $1992,10 \mathrm{pp}$.

${ }^{38} \mathrm{El} 14$ de diciembre de 1992, un juez federal de Los Angeles resolvió que no habían sido presentadas pruebas suficientes para iniciar un proceso contra Humberto Alvarez Machaín, siendo puesto inmediatamente en libertad a pesar de la apelación interpuesta contra esta decisión (vid. diario El País, 15-XII-1992, p. 7; y 16-XII-92, p. 2). Pero este hecho, sin duda relevante para el interesado, no resuelve en absoluto el fondo de la controversia entre los dos Gobiernos si bien la aligera de tensión al tiempo que supone un serio revés para el Gobierno norteamericano. Desconocemos, ante las nuevas circunstancias, si el Gobierno mejicano seguirá adelante con la controversia.
} 


\section{Conclusión}

Ahora bien, a pesar de estos desagradables rebrotes hegemónicos que conviene vigilar, a pesar de las incertidumbres y conflictos provocados por el ascenso del nacionalismo en el Este de Europa, nada hace presagiar cambios fundamentales en el sistema internacional, afectado ahora por un lógico proceso de acomodación de su estructura relacional o interestatal sobre todo en el subsistema regional europeo a causa del apreciable aumento del número de Estados habido en dicho subsistema en el último par de años. Pero estos acontecimientos, insistimos, no afectan a los rasgos esenciales del sistema internacional tal y como estos han quedado definidos entre los años cincuenta y setenta de esta siglo.

Huelga decir que, al hilo de nuestra exposición, se vislumbran otras vías de análisis que hemos descartado conscientemente, como las que giran en torno a las espectativas positivas que abre la situación que acabamos de describir, muy en particular el protagonismo cobrado por la O.N.U. en el mantenimiento de la paz y seguridad internacional gracias al entendimiento que ahora impera en su C. de $\mathrm{S}$. Pero nuestro modesto objetivo era destacar que no es ya riguroso sino sencillamente correcto hablar del nacimiento de un «nuevo orden internacional» de acuerdo con el significado científico normalmente atribuido a esos términos. 